\title{
Impacts on Profitability for the Mexican Strawberry Producers Due to an Increase in Exports to USA
}

\author{
Daniel Hernandez Soto ${ }^{*}$, Alicia Alma Alejos Gallardo, Alicia Casique Guerrero \\ Management and Economic Department, Celaya Institute of Technology, Celaya, Mexico \\ Email address: \\ daniel.hernandez@itcelaya.edu.mx (D.H. Soto),alma.alejos@itcelaya.edu.mx (A. A. A. Gallardo), \\ alicia.casique@itcelaya.edu.mx (A. C. Guerrero) \\ ${ }^{*}$ Corresponding author
}

\section{To cite this article:}

Daniel Hernandez Soto, Alicia Alma Alejos Gallardo, Alicia Casique Guerrero. Impacts on Profitability for the Mexican Strawberry Producers Due to an Increase in Exports to USA. International Journal of Agricultural Economics. Vol. 6, No. 1, 2021, pp. 1-11.

doi: $10.11648 /$ j.ijae.20210601.11

Received: December 7, 2020; Accepted: December 15, 2020; Published: January 4, 2021

\begin{abstract}
USA is the main strawberry importer in the world, so in order to supply the demand in 2018 imported 161,889 t; of which $99.07 \%$ were originally from Mexico. This paper is intended to determine the economic viability of increase the exported quantity of Mexican strawberry to USA by representing the international strawberry market in a partial equilibrium model. According with the calculated price flexibility in 2018 , an increase of $18 \%$ in the strawberry exported quantity to US market causes a decrease in the strawberry international price in $6.6 \%$. With this calculated effects, in a simulated scenario it is estimated that the value of the increase in income due to increase in quantity is USD 98,334,125.89, while the value of the decrease in income due to decrease in price is USD 38,631,068.63. The difference between the two values is an increase of USD $59,703,057.26$. With these estimations, it can be claimed that an $18 \%$ annual increase in the Mexican strawberry exports to USA is viable from an economic perspective. With this scenario, the Benefit-Cost Ratios $(\mathrm{B} / \mathrm{C} \mathrm{R})$ for the producers of Baja California, Michoacan and Guanajuato are 1.98, 1.90 and 0.92 respectively. That is to say, with an annual increase of $18 \%$ in the exported quantity, to produce strawberry for export to USA in Baja California and Michoacan is profitable, while to produce strawberry for export to US market in Guanajuato is not profitable.
\end{abstract}

Keywords: Exports, Imports, International Trade, Strawberry

\section{Introduction}

According to information from the Food and Agriculture Organization (FAO), in 2018 were produced 8,337,099 $\mathrm{t}$ in the world; $46.65 \%$ was harvested in Asia, $26.15 \%$ in America, 20.15\% in Europe, 6.31\% in Africa and 0.75\% in Oceania. In that year, China was the main producer with 2,964,263 t, which represented $35.55 \%$; USA was ranked second with 1,296,272 $\mathrm{t}(15.55 \%)$, Mexico was third with $653,639 \mathrm{t}(7.84 \%)$ and Turkey fourth with 440,968 $\mathrm{t}(5.29 \%)$ [1]. In $2018,10.67 \%$ of strawberry production in the world was destined for export, that is, $889,881 \mathrm{t}$; Spain was the main strawberry exporter with $283,439 \mathrm{t}$, which represented $31.85 \%$ of the world total; USA was ranked second with $152,129 \mathrm{t}(17.09 \%)$, Mexico was third with 124,708 t $(14.01 \%)$ and the Netherlands was fourth with $60,153 \mathrm{t}$ (6.76\%). In 2018, USA was the main strawberry importer in the world with $161,889 \mathrm{t}$, that is, $17.93 \%$ of the world total; while Canada ranked second with 116,315 t (12.88\%), Germany was third with $103,727 \mathrm{t}(11.48 \%)$ and France fourth with $59,887 \mathrm{t}(6.63 \%)$ [1].

According to information from the US Department of Agriculture (USDA), in 2018 USA imported 161,889 t of strawberries, of which $99.07 \%$ were originated in Mexico, that is, $160,368 \mathrm{t} ; 0.76 \%$ came from Canada $(1,231.4 \mathrm{t})$ and $0.14 \%$ from Turkey (229 t) (Table 1) [2].

The annual growth rate of Mexican strawberry imports in USA averaged $8.80 \%$ between 1989 and 2018. Although in the period between 1989 and 2011, the value of the average annual growth rate was $9.87 \%$, while in the period 2012 to 2018 this rate averaged $0.15 \%$. It should be noted that in 2008, 2013, 2015 and 2018, the average annual growth rate 
of Mexican strawberry imports in USA were negative compared to previous years $(-9.28 \%,-5.81 \%,-12.03 \%$ and $3.01 \%$ respectively) as can be seen in Table 1 .

Table 1. Imports of Mexican strawberry in USA from 1989 to 2018.

\begin{tabular}{|c|c|c|}
\hline Year & Tons & Annual rate\% \\
\hline 1989 & $13,881.20$ & \\
\hline 1990 & $12,601.20$ & -9.22 \\
\hline 1991 & $13,041.40$ & 3.49 \\
\hline 1992 & $9,238.00$ & -29.16 \\
\hline 1993 & $12,747.00$ & 37.98 \\
\hline 1994 & $18,923.30$ & 48.45 \\
\hline 1995 & $25,894.30$ & 36.84 \\
\hline 1996 & $29,434.40$ & 13.67 \\
\hline 1997 & $13,744.00$ & -53.31 \\
\hline 1998 & $25,358.10$ & 84.50 \\
\hline 1999 & $42,201.00$ & 66.42 \\
\hline 2000 & $33,116.60$ & -21.53 \\
\hline 2001 & $31,286.00$ & -5.53 \\
\hline 2002 & $39,737.10$ & 27.01 \\
\hline 2003 & $40,227.70$ & 1.23 \\
\hline 2004 & $42,227.30$ & 4.97 \\
\hline 2005 & $54,910.60$ & 30.04 \\
\hline 2006 & $68,945.20$ & 25.56 \\
\hline 2007 & $71,030.10$ & 3.02 \\
\hline 2008 & $64,435.30$ & -9.28 \\
\hline 2009 & $84,291.80$ & 30.82 \\
\hline 2010 & $89,603.80$ & 6.30 \\
\hline 2011 & $110,144.00$ & 22.92 \\
\hline 2012 & $158,913.00$ & 44.28 \\
\hline 2013 & $149,684.30$ & -5.81 \\
\hline 2014 & $161,170.00$ & 7.67 \\
\hline 2015 & $141,778.30$ & -12.03 \\
\hline 2016 & $164,270.70$ & 15.86 \\
\hline 2017 & $165,356.60$ & 0.66 \\
\hline \multirow[t]{2}{*}{2018} & $160,379.80$ & -3.01 \\
\hline & Annual average rate & 8.80 \\
\hline
\end{tabular}

According to information from USDA, Mexico exported $160,379.8 \mathrm{t}$ of strawberries to USA in 2018 [2]. The state of Guanajuato produced in that year $67,188 \mathrm{t}$ of strawberries, of which $30 \%$ (approximately 20,156.4 t) were exported to USA; in Michoacán 417,686 t were produced, $5 \%$ being exported to US market (approximately 20,884.3 t); while Baja California produced 116,451 t, of these $90 \%$ were exported to USA $(104,805.9$ t). That is, between the three states they export $90.94 \%$ of the total of the exports to US market.

Information of the Mexican Ministry of Agriculture and Rural Development (SADER), in 2018, 653,639.24 $\mathrm{t}$ of strawberries were produced in Mexico [3]; and 178,158.28 t were exported, that is, they represented $27.26 \%$ of national production [4]. Likewise, from the 653,639.24 t, 69.60\% were harvested in Michoacán (454,958.46 t), 17.82\% in Baja California $(116,451 \mathrm{t})$ and $10.28 \%$ in Guanajuato $(67,178.72$ t), as can be seen in Table 2 [3].
Table 2. Michoacan, Baja California and Guanajuato comparative 2018.

\begin{tabular}{llll}
\hline & Michoacan & Baja California & Guanajuato \\
\hline Product & $454958 \mathrm{t}$ & $116451 \mathrm{t}$ & $67179 \mathrm{t}$ \\
Annual rate & $5.61 \%$ & $10.74 \%$ & $3.96 \%$ \\
Yield & $45.80 \mathrm{t} / \mathrm{h}$ & $60.65 \mathrm{t} / \mathrm{h}$ & $56.13 \mathrm{t} / \mathrm{h}$ \\
Exports & $20884 \mathrm{t}$ & $104806 \mathrm{t}$ & $20156 \mathrm{t}$ \\
Exp / Production & $5 \%$ & $90 \%$ & $30 \%$ \\
Production cost & $10029 \mathrm{MXN}$ & $12839 \mathrm{MXN}$ & $10379 \mathrm{MXN}$ \\
Producer price & $20424 \mathrm{MXN}$ & $27237 \mathrm{MXN}$ & $10139 \mathrm{MXN}$ \\
\hline
\end{tabular}

The annual growth rate of the national strawberry production averaged $5.76 \%$ in the period $1980-2018$; while in Michoacán the annual rate averaged $5.61 \%$ and in Guanajuato 3.96\%. As regards Baja California, the average annual growth rate in the period $1988-2018$ was $7.99 \%$.

It is worth mentioning that the average annual growth rate of $0.15 \%$ in Mexican strawberry exports to USA during the period 2012-2018 is positive, however, it is much lower than the average annual growth rate of $8.80 \%$ calculated for the period 1989-2018. This decrease in the average annual growth rate in the last seven years is contrary to the expectations of the North American Free Trade Agreement (NAFTA). Under this Agreement, it would be expected that the Mexican strawberry will increase the annual growth rate, improving its competitiveness in the US market, taking advantage of the tariff reduction as well as the evolution of the agri-food safety systems that improve the quality of production to increase the exportable supply. This coupled with the proximity between Mexico and USA that entails competitive advantages in transportation costs.

However, it must be said that between 2011 and 2017 the Apparent National Consumption of strawberries in Mexico grew at an average annual growth rate of $20 \%$, which contributed to slowing the growth rate of exports to USA.

It is important to note that the investigation was carried out before the signing of the new Trade Agreement between Mexico, USA and Canada (T-MEC); so the assumptions presented here do not consider an alternative scenario, with international trade between Mexico and USA outside NAFTA. In this regard, the present work was developed under the prevailing context within NAFTA. The previous situation shows the limitations found for the performance of the work, and the conclusions, since the work must be developed under a specific scenario in which assumptions are made that maintain a significant level of rigidity, while the conditions of uncertainty limit the analysis with an adequate foundation.

However, despite the obstacles described above, the research work presents the opportunity to transfer the results from the partial equilibrium analysis of Mexican strawberry exports to USA to know the financial situation of the producers of strawberry to export in the three main states in Mexico: Baja California, Michoacán and Guanajuato; and once the analysis is done, provide elements to improve this situation.

In this context, we wonder if it is viable for strawberry producers an increase exports to USA in such a way that the average annual growth rate is $18 \%$ (which is approximately 
twice the $8.80 \%$, the average annual growth rate of Mexican exports of strawberries to USA in the period between 1989 and 2018); In other words, if it is viable an increase in Mexican strawberry exports to USA to take advantage of the opportunities that this market offers.

Given the slowdown in the average annual rate, the general objective was to determine the economic viability of increasing the quantity of strawberry exports to USA. To achieve this, it was proposed to represent the Mexican strawberry export market to USA in a partial equilibrium model estimating the price flexibility of demand based on an econometric model and establishing a simulated scenario in which an $18 \%$ increase in the quantity exported to carry out an analysis of the international trade of Mexican strawberries for export to USA and thus determine the viability for Mexican producers to encourage that increase.

As a first hypothesis, it was proposed that it is viable, from the economic perspective, to increase the exported quantity of Mexican strawberries to the US market, even though this increase contributes to a decrease in the price of exports. In this regard, the second hypothesis to be tested is that producing Mexican strawberries for export to USA continues to be profitable in terms of income for producers, given an $18 \%$ annual increase in the quantity exported.

\section{Literature Review}

Williams develops the partial equilibrium analysis in the orange juice market in USA and concludes that a large part of the benefits for orange producers come from the high levels of investment in advertising in the orange juice market [5]. This investment of resources in advertising has effects on two markets: first, advertising increases the demand for orange juice, so the industry increases its consumption of fresh orange, maintaining a "high" price, with the consequent benefits for all the agents involved, including the producer.

Second, as industrial orange consumption increases, the supply of fresh orange decreases, causing an increase in the price for the final consumer. Collaterally, the effects of the price rise are transferred to the international market of fresh orange mainly due to the high levels of orange juice production, as well as the industrial consumption of fresh orange for juice production in USA.

On the other hand, Hernandez, De la Garza and Guzman, through the partial equilibrium analysis of two countries, found that strawberry production in Mexico has opportunities in the export market to USA for high-quality product [6]. In other words, most of the production in Guanajuato and Michoacán is focused on the production of strawberries with intermediate to traditional technology and oriented to the domestic market. While Baja California produce high-quality strawberries through investment in high technology. The study shows that the opportunities in the US market have not been taken advantage of. If in Mexico it is desired to increase the exportable supply of strawberries to the USA to take advantage of market opportunities, the answer must be originated in the modernization to produce top quality strawberries, with which producers obtain additional income (compared to medium quality for the domestic market).

Hernandez and Martinez through partial equilibrium analysis based on the results of an econometric model, estimate that in a scenario of $20 \%$ increase in Mexican mango exports to USA market in 2006 (simulated scenario) with respect to the carried out in 2005, would cause an increase in total income in the international market between Mexico and USA [7].

Taking into consideration that if the $\mathrm{B} / \mathrm{C} \mathrm{R}$ is greater than 1 indicates that the activity is profitable, and transferring this impact to the producer of Michoacán, Sinaloa and Nayarit, the $\mathrm{B} / \mathrm{C} \mathrm{R}$ for the producers of the three states would be $1,003,1,514$ and 3,211 respectively in the simulated scenario. That is, although the $\mathrm{B} / \mathrm{C} \mathrm{R}$ is greater than 1 , in the case of Michoacan it would be very close to the unit, so it can be infered that it is necessary to improve the technological conditions in mango production (improved seed, fertilizers, and safety) in order to increase the yield and reduce the unit production costs. In their analysis, the authors denote that mango producers in Michoacán can bear a $15.6 \%$ decrease in their income, as well as an $18.5 \%$ increase in production costs, which denotes a low margin of tolerance in the increase of exports with a consequent decrease in the price if you want to increase the supply abroad to take advantage of the opportunities in the market. In this regard, they recommend improving the organization mechanisms to promote productive reconversion, emphasizing good agricultural practices, safety, and improving quality; all this in relation to the production conditions in Michoacan.

On the other hand, Hernandez, Lopez and Casique found through partial equilibrium analysis that an annual increase of $20 \%$ in Mexican mango exports to USA is viable from the economic perspective since total income increases [8]. However, when transferring the simulated impacts in quantity and price of this increase in exports to producers in the states of Michoacán and Sinaloa, they estimated that the value of the $\mathrm{B} / \mathrm{C} \mathrm{R}$ would be 1.1806 and 1.1543 respectively, that is, it is still profitable. With regard to Nayarit, the estimated B/C R would be 0.9171 , that is, the revenue would be less than the costs.

Based on these results, they also conclude that to increase income and reduce the unit production cost it is necessary to increase the yield and improve the quality of the product (increase the exportable supply). That is, correct the technological mechanisms for production, such as improved seed, fertilization methods, safety, as well as the modernization of post-harvest management that allows increasing the competitiveness of the exportable supply and taking advantage of opportunities in the international market, specifically in the US market.

The partial equilibrium analysis allows to simulate the effects on the income of producers and consumers in a market of two economies based on the results of an econometric model. Through concepts that have their origin in economic theory, it is possible to apply impacts derived from practice in changes of the fundamental variables 
represented in the model. Through these simulated changes, a response can be made to specific situations that otherwise could not be realized. Furthermore, the partial equilibrium model allows assuming circumstances and changes to analyze the trade of a good between two countries. The results obtained allow knowing elements of the simulated situations, and with them improve the real productive conditions and make decisions on commercial, agricultural and international economic policy.

\section{International Trade Between Two Nations}

When a country can produce a good cheaper than another country, and the latter in turn can produce another good cheaper than the first country, it is beneficial for both countries to specialize in the good that they could produce cheaper, since each country could produce its good more efficiently than the another country. This would cause the quantities produced of each good to exceed the domestic consumption needs of each country where it is produced. The surplus of the production of each good in each country can be destined to the other one since they are not able to consume everything in the domestic market [9].

Trading the surpluses of each good in each country with the other benefits the economy and production efficiency of the two nations. Then both countries, by using the division of labor and producing the merchandise in which each has an absolute advantage, can carry out an exchange at the international level [10].

In the same way that the division of labor improves productivity in a country, the international division of labor favors efficiency at the international level; if one country can produce one good with less work than another, and if the latter can produce some other good with less work than first one, both would lose if they continued to produce both goods. Each one should concentrate on the production of the good that he can produce with less labor cost, or on the production of which it has an advantage, and then exchange its surplus production.

For David Ricardo, even if a nation has an absolute disadvantage in the production of both goods with respect to the other, a favorable exchange for both can still take place. The most efficient nation must specialize in the production and export of the good in which its absolute advantage is greatest. This is the good in which the country has a comparative advantage [9].

On the other hand, a nation must import the good in which its absolute disadvantage is greatest; this is the activity in which it has a comparative disadvantage. Each country specializes in the export of those goods in which it achieves higher relative productivity and then it is possible to obtain generalized benefits from commercial exchange, even if one of the participants produces all the goods at a lower cost than the others. On this basis the Hecksher-Ohlin model is developed. It establishes that each nation must specialize in the export of goods that require a large number of relatively cheaper factors of production [10].

The international division of labor is based on the differences in the climatic-natural conditions of the different countries. This division develops naturally and its basis is the difference in the production costs of the same goods in different countries. In this regard, the cost proportions depend on the relative availability of the factors of production. Then, a country that has a lot of capital will tend to specialize in industrial productions as much more technologically advanced as the capital at its disposal allows. On the other hand, a country that has little capital will specialize in light industries such as textiles or agricultural productions if it also has abundant land as a natural factor, for example [11].

For Krugman and Wells, the goal of a national economy focuses on providing the best standard of living for its citizens, given the endowment of resources that it has [12]. This will depend on the productivity capacity with which these resources are used (labor and capital). They claim that productivity is the main determinant of a nation standard of living in the long run, because it is the root cause of per capita national income. The productivity of human resources determines their wages, while the productivity with which capital is employed determines the return for the capitalist [9].

And so, in international trade it is possible for a country to raise its productivity by eliminating the need to produce all goods and services within the same nation. For this reason, a nation can specialize in those sectors and segments in which its enterprises are relatively more productive and import those products and services in which their enterprises are less productive than their foreign rivals, thus raising the average level of productivity in the country. In this way, imports and exports are a joint factor of productivity growth [11].

With an idealistic perspective, these resources are applied to the most productive uses possible. The specific sectors on which countries base their development depend to a large extent on the country natural resource endowment. Resource-rich countries begin the upgrading process from positions of international success in resource-based sectors. Resource-poor countries have started from positions of success in labor-intensive end-consumer product sectors [10].

The economic success of nations will tend to increase to the extent that the country increases productivity in those goods in which it is efficient in production. However, a country with a vast endowment of natural resources can achieve high national gains despite being in the factor-driven stage, although it is unlikely that it will be able to sustain them indefinitely [9].

Over time, the fact that the country is dependent on natural resources will make the country vulnerable to the exhaustion of new foreign sources or to technological changes that reduce or eliminate the need for this resource. This in turn causes a greater problem, provides high levels of profit that avoids the need for productive development towards subsequent stages based on technology and later on investment [10]. 
International trade theory claims that, in the absence of specific government intervention in foreign trade, the flows of goods and services between countries are determined by market prices. And then the theory of international trade is refered to the study of the specific circumstance in which goods are exchanged between at least two countries with independent economic and monetary systems [11].

The explanation of why goods and services are exchanged between countries has traditionally been the focus of international trade theory. Trade flows are determined by the price differences of each good. The prices of goods are determined by the interaction of supply and demand. Three groups of goods and services can generally be distinguished: international goods, quasi-international goods, and national goods. International goods are basic goods of a homogeneous nature, traded internationally, mainly raw materials and food in which their price tends to equalize. Price and cost differences lead to international division of labor or specialization; and then the production of some goods increases in a country, so they are exported, and the others are reduced because they are imported. This specialization in general is not complete because costs normally increase with increasing production, until reaching a point where the costs of production in the importing country are as low as the price of imports. At this point the division of labor stops [11].

For Ricardo, the trade of a good X between two countries is generated when a country A produces a good at a lower cost than country B, and then, in country B is better to import

Nation A Exporter Country it than to produce it internally. Williams postulates that the exchange of a commodity between two nations is explained through a partial equilibrium model, in which two countries and one good are assumed: an exporter country A, an importer country B and a good X [13].

This model can be explained through the graph of a nation A (exporting country) that has a competitive advantage in the production of good $\mathrm{X}$. In this context, the price $\mathrm{P}_{\mathrm{a}}$ at which this good is produced in the nation $\mathrm{A}$ is relatively lower than the international price IP (and lower than the equilibrium price $\mathrm{P}_{\mathrm{b}}$ of good $\mathrm{X}$ in nation $\mathrm{B}$ ). It is necessary to mention that at price $\mathrm{P}_{\mathrm{a}}$ the quantity demanded $\mathrm{D}_{\mathrm{a}}$ and the quantity supplied $\mathrm{O}_{\mathrm{a}}$ of good $\mathrm{X}$ in nation $\mathrm{A}$ are equal (Figure 1).

Based on the equilibrium price $\mathrm{P}_{\mathrm{a}}$ in nation $\mathrm{A}$, it can be conceived that if this price would tend to increase to the international price IP, the difference between supply $\mathrm{O}_{a}$ and demand $\mathrm{D}_{\mathrm{a}}$ for good $\mathrm{X}$ would tend to increase. This growing difference is seen as an oversupply ES; that is, at a price $\mathrm{P}$ above the equilibrium price $\mathrm{P}_{\mathrm{a}}$, greater quantities of supply are generated that exceed the national demand for good $\mathrm{X}$ in the exporting country A to each price level.

These same excess supply ES generated at different prices, within the international trade model of two countries, can be transferred to a second scenario that represents the international market and a line can be drawn that represents the quantities of good $\mathrm{X}$ available in the foreign market, such as can be seen in Figure 1.

International Market

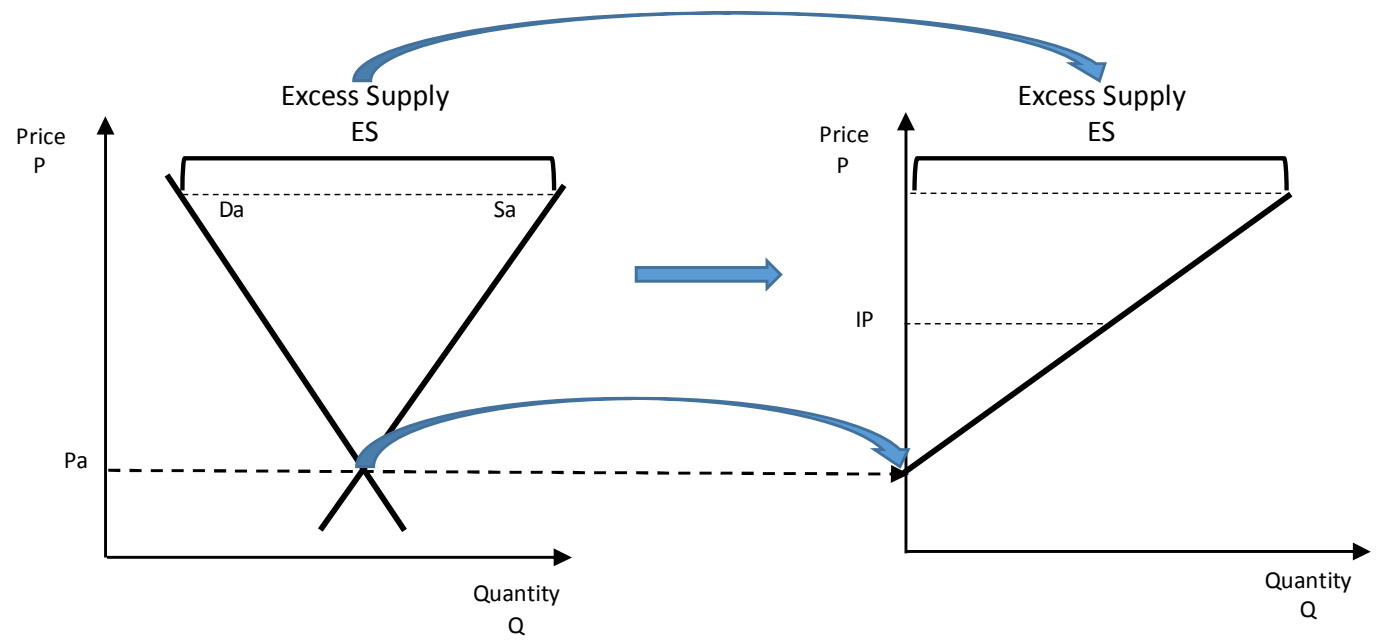

Figure 1. Excess supply for the good $X$ in the international market.

The model also shows the graph of a nation B (importer country) that is at a competitive disadvantage in the production of good $\mathrm{X}$ compared to nation $\mathrm{A}$. In this regard, the price $\mathrm{P}_{\mathrm{b}}$ at which this good is produced in nation $\mathrm{B}$ is higher than the international price IP (and higher than the equilibrium price $\mathrm{P}_{\mathrm{a}}$ of good $\mathrm{X}$ in nation $\mathrm{A}$ ). At this point, it should be noted that at the equilibrium price $P_{b}$ the quantity demanded $D_{b}$ and the quantity supplied $S_{b}$ of good $X$ in nation $B$ are equal (as can be seen in Figure 2).
Now, based on the equilibrium price $\mathrm{P}_{\mathrm{b}}$, it can be conceived that the price $\mathrm{P}$ in nation $\mathrm{B}$ would tend to decrease to the international price IP (lower than the price $\mathrm{P}_{\mathrm{b}}$ in nation $B$ ), the difference between the demand $D_{b}$ and the supply $S_{b}$ of good $\mathrm{X}$ would tend to increase. This difference can be considered as an excess of demand ED; that is, at a Price $\mathrm{P}$ below the equilibrium price $\mathrm{P}_{\mathrm{b}}$, greater amounts of demand are generated that exceed the national supply of good $\mathrm{X}$ in the importer country B to each price level. 


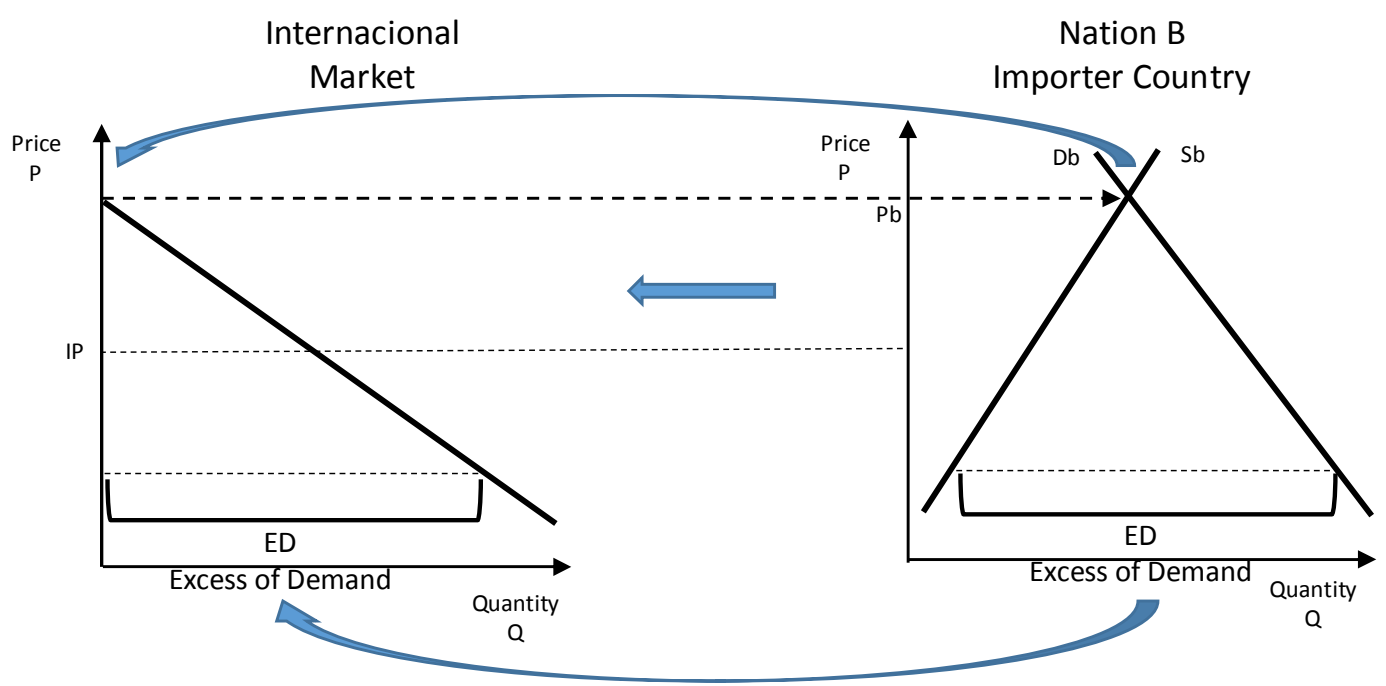

Figure 2. Excess demand for the good $X$ in the international market.

The aforementioned excess demand ED generated at different prices, within the international trade model of two countries, can be transferred to the scenario that represents the international market (mentioned above) in such a way that if a line is drawn that represents the demanded quantities of the good X and missing in the international market (as can be observed in Figure 2).

Now, focusing on the international market scenario, it can be observed in Figure 3 that there is an intersection point between the excess supply ES and the demand in excess ED in which the market equilibrium conditions are fulfilled, since ED and ES are equivalent. At this point then, the international price IP causes an excess supply ES observable in the graph of country A (Figure 1) and an excess demand ED observable also in the graph of country B (Figure 2).

At this level, the excess supply ES and the excess demand ED are equivalent. Then, at the international price IP, the excess supply $S_{a}-D_{a}$ in nation $A$ is equal to the excess demand $D_{b}-S_{b}$ in nation $B$, as can be seen in Figure 4 .

\section{International}

Market

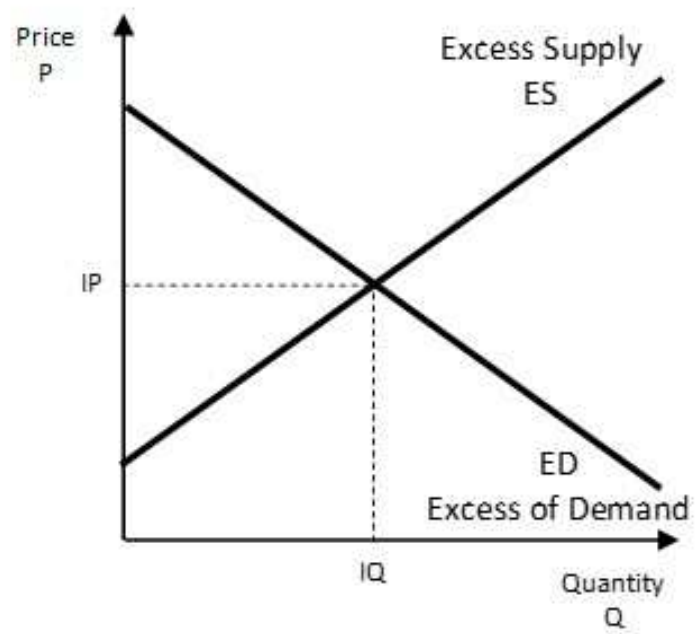

Figure 3. International market for the good $X$.



Figure 4. Exporter country, international market and importer country for the good X. 


\section{Methods}

To develop this work, a descriptive study was carried out, since an account of events was developed that shows the economic impact of an increase in exports of Mexican strawberries to USA. To carry out this analysis, a partial equilibrium of international trade of two countries model was developed.

The study is correlational since to carry out the analysis it is necessary to establish the relationship between the price of Mexican strawberries for export to USA and the quantity exported, for which it was estimated through an econometric model.

In addition, the study is quantitative since the econometric model is based on the statistical relationship between the variables.

\subsection{The Econometric Model}

An econometric model of simultaneous equations was established. The model is composed of the variables and relationships that influence the international strawberry market between Mexico and USA. The equations are:

$$
\begin{aligned}
\text { PIUFUSA }_{\mathrm{t}} & =\beta_{11}+\beta_{12} \text { QIUFUSA }_{\mathrm{t}}+\beta_{13} \text { GDPUSA }_{\mathrm{t}}+\varepsilon_{1 \mathrm{t}} \\
\text { PEUFM }_{\mathrm{t}} & =\beta_{21}+\beta_{22} \text { QEFM }_{\mathrm{t}}+\beta_{23} \text { PPPFM }_{\mathrm{t}}+\varepsilon_{2 \mathrm{t}}
\end{aligned}
$$

Equation (1) is an inverse demand function for strawberry imports in USA where the real CIF import unit price PIUFUSA $_{t}$ is determined by QIUFUSA $_{t}$ and GDPUSA . . QIUFUSA $_{t}$ is the imported quantity of strawberry and, according to economic theory, there is an inverse relationship on PIUFUSA $A_{t}$ determined by a negative sign. In other words, an increase in the quantity imported lowers its price. GDPUSA $_{t}$ is the income in USA measured through the Gross Domestic Product.

Equation (2) is an inverse function of the supply of strawberry exports in Mexico where the real unit export price $\mathrm{PEUFM}_{t}$ is determined by $\mathrm{QEFM}_{\mathrm{t}}$ and $\mathrm{PPPFM}_{\mathrm{t}}$. $\mathrm{QEFM}_{\mathrm{t}}$, is the quantity of strawberry exported in Mexico while PPPFM $_{t}$ is the real average price to the producer of strawberries in Mexico.

The three-stage least squares (3SLS) method was applied to the econometric model of simultaneous equations to estimate the coefficients $\beta 11-\beta 23$ [16]. It is necessary to mention that the time series are made up of 16 observations (years), since it is the maximum amount of information available for the creation of the series.

The PIUFUSAt and QIUFUSAt variables were constructed with information from USDA [2], while the GDPUSAt variable was constructed with data from the US Gross Domestic Product consulted in the Bureau of Economic Analysis (BEA) [14] and the US Census Bureau [15].

The PEUFMt and QEFMt variables were constructed with information from the Mexican Ministry of Economy [4], while the PPPFMt and QPFMEXt variables were constructed with information of the Mexican Ministry of Agriculture and Rural Development [3].

\subsection{The Partial Equilibrium Model}

The average annual growth rate of Mexican strawberry imports in USA in the period between 1989 and 2018 was calculated as can be seen in (3):

$$
T C P A_{1989-2018}=\left[\left(\sqrt[29]{\frac{160367.6}{13881.2}}\right)-1\right] * 100=8.80 \%
$$

While the calculation of the average annual growth rate of Mexican strawberry imports from 2012 to 2018 was carried out as can be seen in (4):

$$
T C P A_{2012-2018}=\left[\left(\sqrt[6]{\frac{160367.6}{158913.0}}\right)-1\right] * 100=0.15 \%
$$

As can be seen in Table 1, the average rate of Mexican strawberry exports to USA between 1989 and 2018 grew approximately $8.80 \%$ annually; while between 2012 and 2018 the growth rate averaged $0.15 \%$ annually.

With this background and with the idea that an increase in exports may contribute to a decrease in the price of Mexican strawberries in the US market, an increase in the exported quantity was simulated, considering its impact on the profitability for Mexican producers, and thus determine the viability of increasing the exported quantity to the US market.

In this analysis, the following assumptions were established: a good: the strawberry, an international market of two countries: Mexico and USA, the relationship of each country of the model with the rest of the world is considered as part of each one separately, the excess of demand ED for strawberries in the USA is equal to imports of Mexican strawberries, the excess supply ES of strawberries in Mexico is equal to exports to US market, US dollars values, prices and values in real terms, and an $18 \%$ increase in Mexican strawberry exports to US market in 2019 compared to those made in 2018. 18\% represents approximately twice the average annual growth rate of the quantity exported in the period between 1989 and 2018 (Table 1).

The partial equilibrium model is based on the analysis of the international export orange juice market in USA carried out by Williams [3].

In Figure 5 it can be observed that an increase in the quantity supplied in Mexico of strawberries for export to USA from $Q_{a 0}$ to $Q_{a 1}$ is reflected in the graph as a shift in the supply curve $\mathrm{O}_{\mathrm{a} 0}$ to $\mathrm{O}_{\mathrm{a} 1}$, resulting in turn in a shift in the curve of excess supply ES in the international market.

This also causes a decrease in the international price from $\mathrm{IP}_{0}$ to $\mathrm{IP}_{1}$, and in turn, an increase in the traded quantity in the international market from $\mathrm{IQ}_{0}$ to $\mathrm{IQ}_{1}$, observing an increase in excess demands ED for strawberry in USA.

\subsection{Price Flexibility of Demand}

Then, with the results of the econometric model, the price flexibility of demand was calculated as follows: 


$$
F_{\text {QIUFUSA }}^{\text {PIUFSA }}=\left(\frac{d P I U F U S A}{d Q I U F U S A}\right)\left(\frac{Q I U F U S A}{P I U F U S A}\right)
$$

The price flexibility of the demand allows knowing the percentage decrease in the price in the face of an increase of $1 \%$ in the traded quantity (for the case of the international market). Therefore, with this estimation it is possible to calculate the percentage decrease in the price in the face of an $18 \%$ increase in the traded quantity.

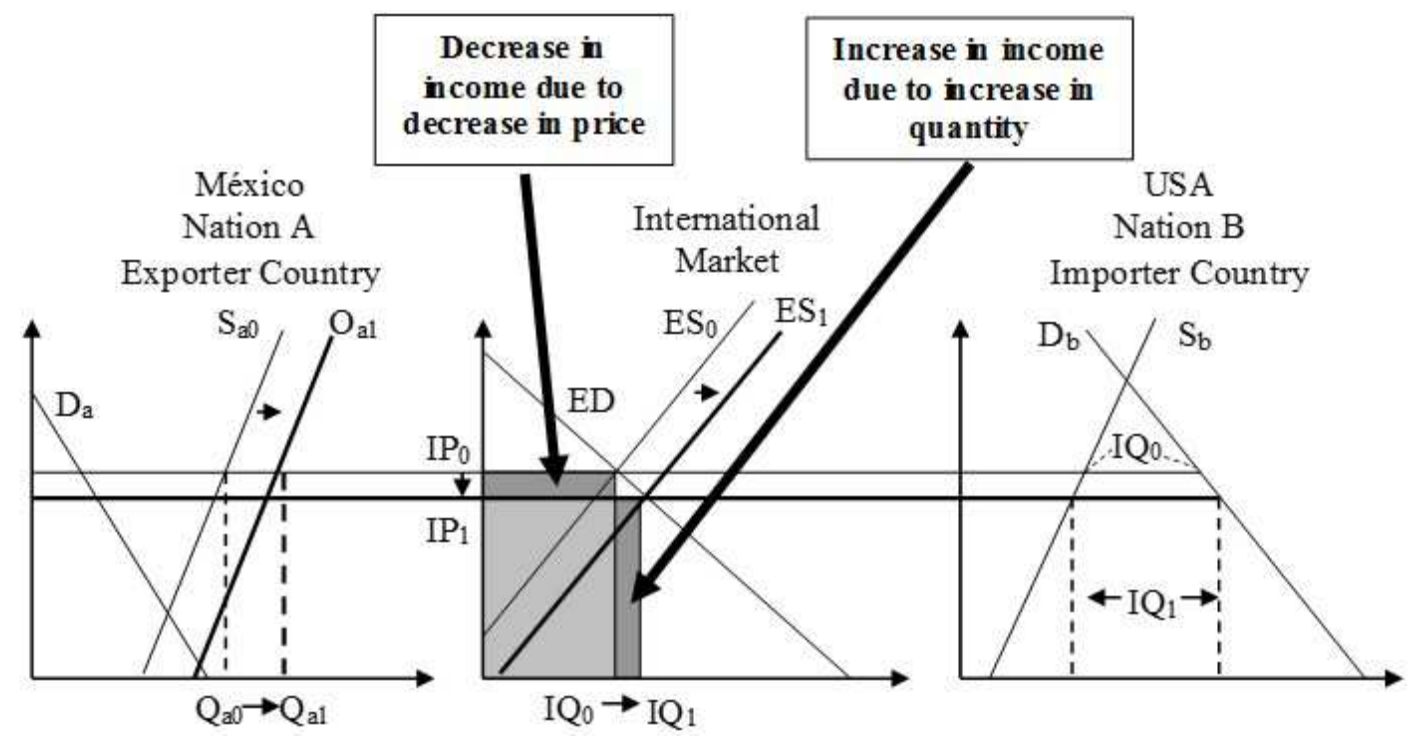

Figure 5. Increase in the exported quantity of Mexican strawberries to USA.

\subsection{The Simulated Final Impact}

Now, to estimate both effects in the international market, the Increase in income due to increase in quantity and the Decrease in income due to decrease in price was calculated as follows:

Increase in income due to increase in quantity

$$
\text { (II) }=\left(Q_{1}-Q_{0}\right) P_{1}
$$

Decrease in income due to decrease in price

$$
(\mathrm{DI})=\left(\mathrm{P}_{0}-\mathrm{P}_{1}\right) \mathrm{Q}_{0}
$$

Understanding that the difference between the increase and the decrease in income will allow knowing the balance of both impacts, it was calculated as follows:

Balance

$$
\text { II - DI }=\text { Profit or Loss }
$$

The final value calculated in (8) allows determining the final effect of the $18 \%$ increase in the quantity exported. The criteria to determine the viability of increasing Mexican strawberry exports to USA are:

1. If the II is greater than the DI the final result (8) will have a positive sign. Thus, an annual increase that represents an average growth rate of $18 \%$ in Mexican strawberry exports to USA is viable from an economic perspective. This means that an average annual growth rate of $18 \%$ will increase total revenue.

2. If the II is lower than the DI the final result (8) will have negative sign. Therefore, an annual increase that represents an average growth rate of $18 \%$ in Mexican strawberry exports to the USA is not viable from an economic perspective. This means that an average annual growth rate of $18 \%$ will reduce total revenue.

\subsection{The Benefit / Cost Ratio}

Now, to analyze the effects on the profitability for the producer, the simulated impacts of the increase in the quantity $(18 \%)$ and the decrease in price $(6.6043 \%)$ were transferred to the $\mathrm{B} / \mathrm{C} \mathrm{R}$ analysis for the strawberry producer in the states of Baja California, Michoacán and Guanajuato; considering that the three states represent $90.94 \%$ of the Mexican strawberry exports to the US market. The B/C R was calculated as can be seen in (9):

$$
\mathrm{B} / \mathrm{C} \mathrm{R}=\text { Benefit } / \text { Cost Ratio }
$$

The criteria to determine the viability of an increase in the exported quantity from the perspective of the producer in the exporter country are:

$$
\begin{aligned}
& \mathrm{B} / \mathrm{C} \mathrm{R}>1 \text { It is profitable } \\
& \mathrm{B} / \mathrm{C} \mathrm{R}=1 \text { There is no profit or loss } \\
& \mathrm{B} / \mathrm{C} \mathrm{R}<1 \text { It is not profitable }
\end{aligned}
$$

\section{Results and Discussion}

With the results of the econometric model of simultaneous equations, the following coefficients $\beta$ were obtained: 
Table 3. Coefficients calculated with the results of the econometric model.

\begin{tabular}{llll}
\hline Coefficient & Value & t value & Pr $>\mathbf{t}$ \\
\hline$\beta_{11}$ & -1769.000000 & -2.28 & 0.0402 \\
$\beta_{12}$ & -0.007740 & -2.01 & 0.0662 \\
$\beta_{13}$ & $3.28 \mathrm{E}-10$ & 4.53 & 0.0006 \\
$\beta_{21}$ & 1971.748000 & 5.96 & 0.0001 \\
$\beta_{22}$ & 0.0070470 & 7.17 & 0.0001 \\
$\beta_{23}$ & -1.051230 & -2.68 & 0.0189 \\
\hline
\end{tabular}

Once the $\beta$ 's have been estimated, the specific QIUFUSA $A_{t}$ coefficient can be known in the demand function:

$$
\text { PIUFUSA }_{\mathrm{t}}=\beta_{11}-0.00774 \text { QIUFUSA }{ }_{\mathrm{t}}+\beta_{13} \text { GDPUSA }+\varepsilon_{1 \mathrm{t}}
$$

To calculate the price flexibility of the demand, the partial derivative of the demand function (13) with respect to QIUFUSA $_{t}$ was estimated as follows:

$$
\left(\frac{d P I U F U S A}{d Q I U F U S A}\right)=-0.007740
$$

Once the partial derivative was obtained, it was multiplied by the quotient of the average values of QIUFUSA $t$ and PIUFUSA $_{t}$ to calculate the price flexibility of the demand:

$$
F_{\text {lIUFUSA }}^{\text {PIFSA }}=\left(\frac{\text { dPIUFUSA }}{\text { dQIUFUSA }}\right)\left(\frac{\text { QIUFUSA }}{\text { PIUFUSA }}\right)=(-0.007740)\left(\frac{108615.8}{2291.26308}\right)=-0.36690954
$$

Regarding the price flexibility of the demand, it can be established that the imported quantity of Mexican strawberry in USA QIUFUSA $\mathrm{t}_{t}$ presents a negative and inflexible relationship with respect to the unit import price of

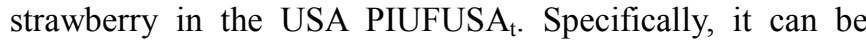
stated that when faced with a $1 \%$ increase in the quantity demanded, the price decreases $0.3669 \%$.

Now, to determine the decrease in price due to the increase in the quantity demanded, and the final effect as a result of an $18 \%$ increase in the exported quantity, based on the price flexibility of Mexican strawberry imports in USA, flexibilities were calculated, as shown in Table 4.

Table 4. Price flexibility of the demand for strawberry imports in USA.

\begin{tabular}{cl}
\hline $\begin{array}{l}\text { Change in the imported quantity } \\
\text { of strawberry }\end{array}$ & $\begin{array}{l}\text { Change in the price of imported } \\
\text { strawberry }\end{array}$ \\
\hline $1.0000 \%$ & $-0.3669 \%$ \\
$18.0000 \%$ & $-6.6043 \%$ \\
\hline
\end{tabular}

The percentage response of the price to an increase in the quantity demanded of $18 \%$ then, for the simulated 2019 scenario, would be a decrease of $6.6043 \%$ with respect to the 2018 price, as can be seen in Table 5 .

Table 5. Simulated 2019 scenario with $18 \%$ increase in quantity.

\begin{tabular}{lllr}
\hline t & Quantity Q & Price P & (Q) (P) \\
\hline 2018 & $160,379.80$ & $3,647.16$ & $584,931,768.00$ \\
2019 & $189,248.16$ & $3,406.29$ & $644,634,825.26$ \\
Increase & & & $59,703,057.26$ \\
\hline
\end{tabular}

Note in Figure 5, that when imported quantity increases in USA from $\mathrm{Q}_{0}$ to $\mathrm{Q}_{1}$, there is an increase in income due to the increase in the traded quantity, but there is also a decrease in income due to the decrease in the price when price shifts from $\mathrm{P}_{0}$ to $\mathrm{P}_{1}$. Then the areas shown are calculated, estimating the balance, this is, the final impact on the income (Table 6).

As can be seen, if the increase in income due to increase in quantity is greater than the decrease in income due to decrease in price, there is a positive effect on the global impact; which is equivalent to US\$ 59,703,057.26.

Table 6. Final impact on the value of Mexican strawberry exports to USA.

\begin{tabular}{lc}
\hline Area & Value in US\$ \\
\hline Increase in income due to increase in quantity: $\left(\mathrm{Q}_{1}-\mathrm{Q}_{0}\right) \mathrm{P}_{1}$ & $98,334,125.89$ \\
Decrease in income due to decrease in price: $\left(\mathrm{P}_{0}-\mathrm{P}_{1}\right) \mathrm{Q}_{0}$ & $-38,631,068.63$ \\
Final impact & $59,703,057.26$ \\
\hline
\end{tabular}

With the calculation of the price flexibilities of the demand, it is observed that in the face of an $18 \%$ increase in the imported quantity, the value of the increase in income due to increase in quantity is US\$ $98,334,125.89$, while the value of the decrease in income due to decrease in price is US\$ $38,631,068.63$. The difference between the two values is an increase of US\$ 59,703,057.26.

Now, to determine the viability for the Mexican producer of an increase of $18 \%$ in the traded quantity in the international market, the $\mathrm{B} / \mathrm{C} \mathrm{R}$ of the year 2018 and the hypothetical scenario of the year 2019 were compared. It is assumed a linear cost function, so the cost per $t$ is constant.

Table 7. Benefit-Cost Relationship for the Mexican producer in 2018.

\begin{tabular}{lrcc}
\hline State & Income MXN & Expenses MXN & B/C R \\
\hline Baja California & $2,854,595154$ & $1,345,602,950$ & 2.1214 \\
Michoacan & 426,549714 & $209,448,644$ & 2.0365 \\
Guanajuato & 208,679209 & $209,203,275$ & 0.9974 \\
\hline
\end{tabular}

With these results (Table 7) it can be observed that the $\mathrm{B} / \mathrm{C}$ $\mathrm{R}$ for the producers of Baja California, Michoacan and Guanajuato are 2.1214, 2.0365 and 0.9974 for the year 2018. That is, for the producers of Baja California and Michoacan it is profitable produce strawberry for export to USA; while for Guanajuato producers is not profitable.

Now, with the results of the simulated scenario 2019 (Table 8), it can be claimed that in the face of an increase of $18 \%$ in the quantity exported and a decrease of $6.6043 \%$ in the price (compared to 2018), the B/C R estimation for the producers of Baja California, Michoacan and Guanajuato are $1.9813,1.9020$ and 0.9234 respectively; which indicates that an $18 \%$ increase in the exported quantity is still profitable for producers in Baja California and Michoacán. However, for the Baja California producer, an $18 \%$ increase in the exported quantity causes the profitability declines even more.

Table 8. Benefit-Cost Relationship for the Mexican producer in the 2019 simulated scenario.

\begin{tabular}{llll}
\hline State & Income MXN & Expenses MXN & B/C R \\
\hline Baja California & $3,145,959,194$ & $1,587,811,455$ & 1.9813 \\
Michoacan & $470,086,758$ & $247,149,360$ & 1.9020 \\
Guanajuato & $227,945,278$ & $246,859,844$ & 0.9234 \\
\hline
\end{tabular}

It is worth mentioning that the analysis of international 
trade of a good between two countries through the partial equilibrium model allows the identification of simulated impacts on the market variables considered in an econometric model. The calculation of the price elasticity of demand and the price flexibility of demand allow simulating impacts on the market. Capps, Williams and Dang found that in the US lamb market the income for producers is higher than the costs incurred in promotion [18]. They affirm that the efforts in advertising cause an increase in demand that in turn increases the benefits for producers, derived from the increase in sales. This effect also increases the price of lamb imports in US market as a result of the positive shift of excess demand in the international market.

On the other hand, Hernandez, Lopez and Casique show that an increase in Mexican mango exports to the US market has a positive final impact [8]. In other words, the mango international market between the two countries allows the traded quantity to increase at an annual rate of $20 \%$, obtaining a profit derived from international trade. However, it is necessary to mention that this final effect is the balance, since the increase in the traded quantity causes a shift of the excess supply in the international market and an increase in income, but, as a consequence of the aforementioned shift, the international price decreases, which causes a decrease in income.

The final impact is the difference between the increase in income due to the increase in quantity, and the decrease in income due to the decrease in price. The difference has a positive sign because the increase is greater than the decrease in income, therefore the final impact is positive. That is, the final result is benefits for both countries in international trade.

It is worth mentioning that two repercussions can be identified as a result of the simulated increase in the exported quantity of Mexican mango to the US market: the final impact is positive, that is, a gain as a result of the international mango trade between both countries; and, on the other hand, a decrease in the $\mathrm{B} / \mathrm{C} \mathrm{R}$ for the mango producer in Mexico. In summary, the benefits of this simulated increase in the exported quantity of mango are mainly for the consumer in USA; while the profitability for the mango producer in Mexico decreases.

The importance of this analysis falls on identifying the opportunities of the product in the international market between two countries. In this regard, an alternative scenario can be assumed: if the final impact on the international market of a good had a negative sign, that is, the decrease in income due to the decrease in the international price were greater than the increase in income due to the increase in the quantity exported. In this case, the increase in the exported quantity would cause losses in international trade between both countries, in addition to reducing profitability for the producer in the exporter country.

This scenario can be interpreted as a market with a high level of saturation, in such a way that increasing the quantity exported to levels greater than the current ones would cause losses for both countries because the market of the importer country no longer is capable to consume larger amounts of the good than current ones. In other words, in this hypothetical scenario, the opportunities to increase exports to the import market are very low; so the market strategy of the exporter country should focus on finding new markets.

It is worth mentioning that Avila and Gonzalez [17] found that between 2003 and 2009 Mexican strawberry exports lost $20 \%$ of competitiveness in the US market, based mainly on the value of exports (slow growth of the average annual rate, thus as a decrease in the real unit price). In other words, although there is growing demand and little competition from other countries, Mexico response capacity to maintain sustained growth in strawberry exports year after year to the US market is insufficient to take advantage of the opportunities it offers.

It is worth mentioning the analysis carried out by Hernandez, De la Garza and Guzman [6], in which they showed that a $30 \%$ increase in the quantity of strawberry exported to USA increases the income and decreases it due to the decrease in price. However, in the final balance, there is an increase in income for the international market of the two countries. On the other hand, the simulated impact causes a decrease in B/C R for strawberry producers to export in Baja California, Michoacán and Guanajuato, estimating values of $1.3567,1.4207$ and 1.1249 respectively for 2008 .

Taking these results as a reference and comparing them with those obtained in the present investigation 11 years later, Baja California and Michoacan producers have increased their competitiveness in the production of strawberries for export to USA. Meanwhile, for Guanajuato producers, grow strawberries for export to the US market has stopped being profitable.

\section{Conclusions}

The estimated price flexibility shows that in the face of an $18 \%$ increase in the quantity exported to USA, the price decreases by $6.6 \%$. With these results, it is estimated that the increase in income due to increase in quantity is greater than the decrease in income due to decrease in price. The difference between the two values is a final increase of US\$ 59,703,057.26. With these estimates, it can be claimed that an incentive policy for Mexican strawberry exports in USA, resulting in an increase of $18 \%$ in one year, is viable.

Now, it was estimated that in 2018 the $B / C$ R for the producers of Baja California, Michoacan and Guanajuato were $2.1214,2.0365$ and 0.9974 respectively. While in 2019 (simulated scenario), it was estimated that the B/C R would be $1.9813,1.9020$ and 0.9234 respectively for those same states. So, with these results, it can be assumed that it is profitable for producers in Baja California and Michoacán to grow strawberries for export to USA. In this regard, an $18 \%$ annual increase in the quantity exported allows maintaining an acceptable profitability.

However, for the Guanajuato producer, it is not profitable to grow strawberries for export to USA from the perspective of $\mathrm{B} / \mathrm{C} \mathrm{R}$, since an $18 \%$ increase in the quantity exported in 
one year causes profitability to decline even more.

In this condition, it is convenient to develop an agricultural policy in relation to the production of fresh strawberries in Guanajuato for export to USA that is based on technological improvement mechanisms that increase production, but accompanied by strategies that increase the exportable supply, that is, raise the technological levels of the production systems so that the quality standards and organoleptic characteristics required by the US market are met. In this way, exportable production must increase the price in the US market, increasing the income of Mexican producers, thus offsetting the cost of investments in technological development.

It is necessary to mention that these reflections and the established conditions are made with data analyzed under NAFTA. The assumption of this work is that the international trade conditions under the T-MEC Agreement (which entered into force on July 1,2020) will be the same to the next years.

It is assumed that the conclusions derived from this analysis remain valid for the next years. Despite that, it is highly recommended to carry out a new analysis to identify the real impacts of the T-MEC on the strawberry market and determine at that time if the circumstances and conditions under T-MEC change the reflections made here.

\section{References}

[1] Food and Agricultural Organization (FAO). Faostat. 2020.

[2] United States Department of Agriculture (USDA). Foreign Agricultural Service on line. 2020.

[3] Ministry of Agriculture and Rural Development (SADER). Agrifood and Fisheries Information Service. 2020.

[4] Ministry of Economy (SE). Tariff Information System Via Internet. 2020.

[5] G. W. Williams, International Agribusiness Trade Analysis. Texas A\&M. 2006
[6] D. Hernandez S., M. T. De la Garza C., E. Guzman S. Competitiveness of the Mexican strawberry for export to USA: a partial equilibrium model. Journal of Globalisation, Competitiveness and Governability. Universia. 5 (3). 102-114, 2011.

[7] D. Hernandez S. and M. A. Martinez D. Procedure for a partial equilibrium analysis of the Mexican mango (Mangifera indica) exports to USA. Revista Fitotecnia Mexicana. 32 (3). 251-256. 2009.

[8] D. Hernandez S., F. J. Lopez Ch., A. Casique G. A Partial Equilibrium Analysis of Mexican Mango Exports to the United States. Revista Agricultura, Sociedad y Desarrollo. 17 (1). 171-199. 2020.

[9] R. J. Carbaugh. International economy. Cengage Learning. Mexico. 15-21, 30-31, 68-70. 2009.

[10] P. R. Krugman, M. Obsfeld, M. J. Melitz, International economy. Spain, Pearson. 22-28. 2012.

[11] R. Torres G., Teoría del comercio internacional. México. SXXI. 200-202, 226-228. 2011.

[12] P. R. Krugman and R. Wells. Introductión to economícs. Spain. Reverté. 14-16. 2010.

[13] G. W. Williams. International Agribusiness Trade Analysis. Texas A\&M University. 2020.

[14] BEA (Bureau of Economic Analysis). US Economic Accounts. 2020.

[15] US Census Bureau. Population Finder on line. 2020.

[16] D. N. Gujarati, and D. C. Porter. Econometrics. México: McGraw-Hill. 2010.

[17] A. Avila A., A. and D. J. Gonzalez M. Competitiveness of mexican strawberries (fragaria spp.) in the national, regional and USA market. Revista Agricultura, Sociedad y Desarrollo. 9 (1). 17-27.

[18] O. Capps Jr., G. W. Williams and T. Dang. Effects of lamb promotion on lamb demand and imports. Reports 90492, Texas A\&M University, Agribusiness, Food, and Consumer Economics Research Center. 2010. 